\title{
Desempenho produtivo e características de carcaça de ovinos mantidos em pastos de duas cultivares de capim-bufel manejados em três ofertas de forragem
}

\author{
Productive performance and carcass characteristics of lambs grazing on pastures of \\ two cultivars of buffel grass and three forage allowance
}

\author{
OLIVEIRA, Rogério Gonçalves de ${ }^{1 *}$; VOLTOLINI, Tadeu Vinhas ${ }^{2}$; MISTURA, \\ Cláudio $^{3}$; MORAES, Salete Alves de ${ }^{4}$; SOUZA, Rafael Araújo ${ }^{5}$; SANTOS, Betina \\ Raquel Cunha dos ${ }^{6}$
}

\author{
${ }^{1}$ Doutor em zootecnia, Profissional autônomo, Petrolina, Pernambuco, Brasil. \\ ${ }^{2}$ Embrapa Semiárido, Petrolina, Pernambuco, Brasil. \\ ${ }^{3}$ Universidade Estadual da Bahia, Juazeiro, Bahia, Brasil. \\ ${ }^{4}$ Embrapa Semiárido, Petrolina, Pernambuco, Brasil. \\ ${ }^{5}$ Mestre em zootecnia, Profissional autônomo, Petrolina, Pernambuco, Brasil. \\ ${ }^{6}$ Universidade Federal do Acre, Rio Branco, Acre, Brasil. \\ *Endereço para correspondência: rogeriogoncalves@zootecnista.com.br
}

\section{RESUMO}

Objetivou-se com este estudo avaliar o consumo de forragem, o desempenho produtivo (ganho médio diário, ganho de peso total e peso corporal final), os parâmetros de carcaça (peso de carcaça quente e rendimento de carcaça quente), além da taxa de lotação e do ganho de peso por unidade de área de pastos de capim-bufel (Cenchrus ciliaris L.) pastejados por ovinos. $\mathrm{O}$ trabalho foi realizado no período de setembro de 2009 a agosto de 2010 , com o pasto manejado em lotação contínua. Os tratamentos constituíram-se de combinações de duas cultivares de capim-bufel (Biloela e Cpatsa $7754)$ e três ofertas de forragem $(4,8$ e $12 \mathrm{~kg}$ de matéria seca/100kg de peso corporal ou 4,8 e $12 \%$ ) em arranjo fatorial $3 \times 2$ e delineamento em blocos completos casualizados com três repetições. As variáveis relacionadas com o consumo de forragem, desempenho produtivo do animal, características da carcaça, taxa de lotação e ganho de peso por unidade de área não foram afetadas pelas cultivares, ofertas de forragem e interação entre ofertas de forragem e cultivares. Em média os ovinos apresentaram $452,14 \mathrm{~g} / \mathrm{animal} / \mathrm{dia}$ de consumo de forragem, 59,77g/animal/dia de ganho médio diário, 41,51\% de rendimento de carcaça quente, enquanto os pastos permitiram em média 11,78 ovinos/ha com a obtenção de $205,64 \mathrm{~kg} / \mathrm{ha} /$ ano de ganho de peso.

\section{SUMMARY}

The objective of this present trial was to evaluate the forage intake, productive performance of lambs (average daily gain, total weight gain and final body weight), the carcass characteristics (hot carcass weight and hot carcass dressing), besides stocking rate and weight gain by area of buffel grass pastures (Cenchrus ciliaris L.) grazing by lambs. This trial was carried out during September 2009 to Ausgust 2010, using continuos stocking. The treatments were combinations of two cultivars of buffel grass (Biloela and Cpatsa 7754) and three forage allowance $(4,8$ and $12 \mathrm{~kg}$ of dry matter/100 kg of body weight or 4,8 and $12 \%$ ) in $3 \times 2$ factorial arrangement and completely randomized blocks with three replicates. The variables related to forage intake, produtive performance, carcass characteristics, stocking rate and weight gain by area did not affect by cultivars, forage allowance and interation between cultivars and forage allowance. The lambs presented 452,14 g/animal/day of dry matter intake, $59,77 \mathrm{~g} / \mathrm{animal} /$ day of average daily gain, $41,51 \%$ of hot carcass dressing, while buffel grass pastures had 11,78 lambs/ha and promoted 205,64 kg/ha/year of weight gain.

Keywords: sheep breeding, graze, semiarid

Palavras-chave: ovinocultura, pastejo, semiárido 


\section{INTRODUÇÃO}

A pecuária tem grande importância econômica e social para o Semiárido brasileiro, porém, um dos grandes entraves à produção pecuária nessa região é a escassez de alimentos aos animais, sobretudo na época seca do ano. A vegetação nativa (Caatinga), em geral se constitui na base alimentar aos rebanhos e na maioria das situações não é suficiente para atender as demandas nutricionais dos ruminantes em quantidade e qualidade de forragem, ocasionando baixos índices zootécnicos e de rentabilidade na atividade (SANTOS et al., 2011).

Nesse caso, o cultivo e uso de plantas forrageiras alternativas é uma estratégia que pode contribuir com a redução das deficiências alimentares aos animais, em que uma das que merecem destaque é o capim-bufel (Cenchrus ciliaris L.) (VOLTOLINI et al., 2010; VOLTOLINI et al., 2011; SILVA et al., 2011).

Essa planta forrageira com elevada resistência a seca (MEDEIROS \& DUBEUX JUNIOR, 2008) pode apresentar produção de forragem da ordem de $12.000 \mathrm{~kg}$ de matéria seca (MS)/ha/ano com teores de proteína bruta (PB) superiores a $10 \%$ da MS e valores de digestibilidade in vitro da MS próximos a $60 \%$ da MS, ou seja, valores considerados como relevantes para áreas áridas e semiáridas (VOLTOLINI et al., 2011). Na prática, o capim-bufel é a principal gramínea forrageira cultivada em importantes regiões produtoras de ruminantes do Semiárido brasileiro.

Apesar da importância do capim-bufel para regiões secas, informações e estratégias relacionadas com o manejo do pastejo dessa espécie forrageira são escassas, especialmente no Semiárido brasileiro, independente das cultivares como a Biloela, a Cpatsa 7754 e a Aridus.
Sabe-se que a frequência e a intensidade de pastejo pode afetar as características produtivas e qualitativas dos pastos, o que reflete na eficiência de uso da forragem produzida e na vida útil das pastagens (SILVA et al., 2011). Alterações nos valores de oferta de forragem (OF) que refletem em mudanças nas intensidades de pastejos podem promover importantes modificações na composição morfológica e estrutural do dossel forrageiro, na composição botânica dos pastos, o que em consequência pode afetar o consumo de forragem, a composição química da planta forrageira e o desempenho dos ruminantes em pastejo (ALMEIDA et al., 2000; ANDRADE et al., 2007).

Dessa forma, objetivou-se com este trabalho avaliar as características produtivas e qualitativas de pastos de duas cultivares de capim-bufel, manejados em três ofertas de forragem pastejados por ovinos.

\section{MATERIAL E MÉTODOS}

O estudo foi realizado no período de setembro de 2009 a agosto de 2010, no Campo Experimental da Caatinga, pertencente a Embrapa Semiárido em Petrolina-PE. A área está localizada a $9^{\circ}$ 24" 38" de latitude Sul, $40^{\circ} 29 " 56 "$ de longitude Oeste e apresenta altitude de $377 \mathrm{~m}$, temperatura média anual de $26^{\circ} \mathrm{C}$, umidade relativa do ar média anual de $60 \%$ e precipitação média anual de $522 \mathrm{~mm}$.

A região possui clima Semiárido do tipo BSswh', conforme classificação de Köppen. As variáveis climáticas de precipitação, temperatura e umidade relativa do ar, referentes ao período experimental foram obtidas na Estação Agrometeorológica da Embrapa Semiárido (EMBRAPA, 2011), localizada a aproximadamente $500 \mathrm{~m}$ da área experimental (Figura 1). 


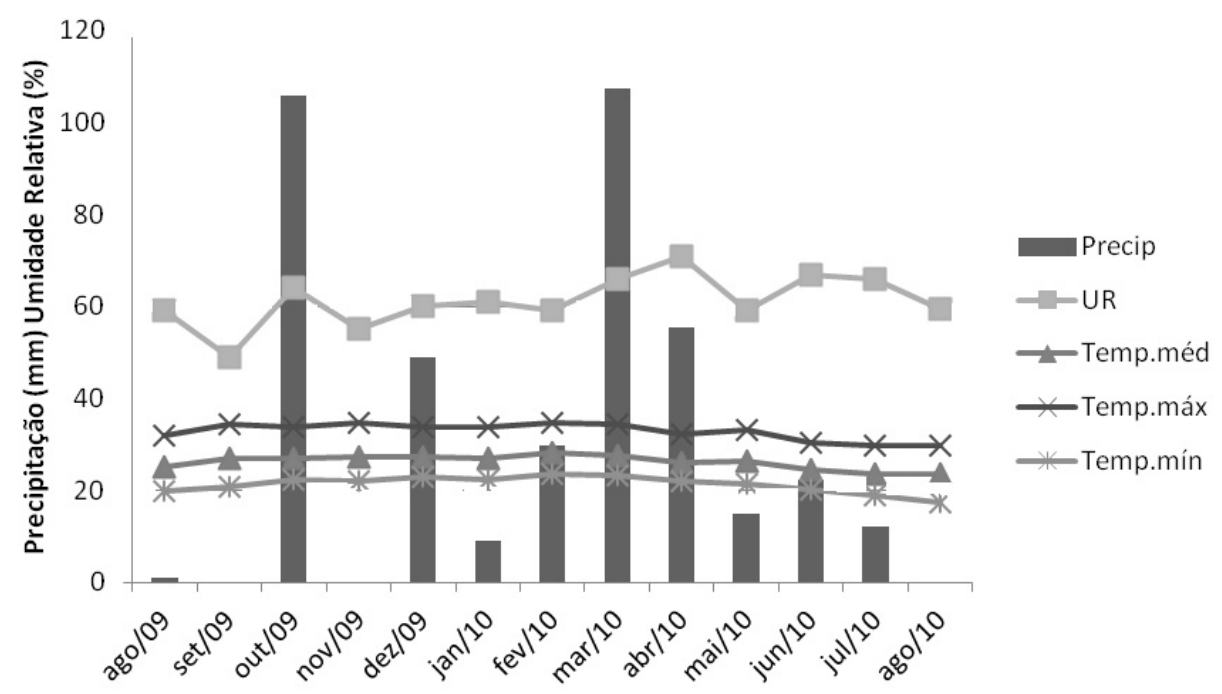

Figura 1. Precipitação $(\mathrm{mm})$, umidade relativa $(\%)$, temperaturas média, máxima e mínima $\left({ }^{\circ} \mathrm{C}\right)$ referente ao período de agosto de 2009 a agosto de 2010 (Fonte: Embrapa Semiárido)

Foi utilizada área de 5,4 hectares de capim-bufel (Cenchrus ciliaris L.) dividida em 18 piquetes de 0,3 hectares. O solo é classificado como Latossolo Vermelho-amarelo distrófico segundo o Sistema Brasileiro de Classificação de Solos (EMBRAPA, 2006) e apresentou as seguintes características químicas, na camada de $0-20 \mathrm{~cm}$ de profundidade, no início do estudo: $\mathrm{pH}=5,5$; matéria orgânica $=8,27 \mathrm{~g} / \mathrm{kg} ;$ conduvidade elétrica $=1,61 \mathrm{dS} / \mathrm{m}$; fósforo $=$ $17 \mathrm{mg} / \mathrm{dm}^{3} ;$ potássio $=0,44 \mathrm{cmol}_{\mathrm{c}} / \mathrm{dm}^{3}$; cálcio $=2,3 \mathrm{cmol}_{\mathrm{c}} / \mathrm{dm}^{3} ;$ magnésio $=$ $0,9 \mathrm{cmol}_{\mathrm{c}} / \mathrm{dm}^{3} ;$ sódio $=0,03 \mathrm{cmol}_{\mathrm{c}} / \mathrm{dm}^{3}$; alumínio $=0,05 \mathrm{cmol}_{\mathrm{c}} / \mathrm{dm}^{3}$; alumínio e hidrogênio $=2,31 \mathrm{cmol}_{\mathrm{d}} / \mathrm{dm}^{3}$; soma de bases $=3,67 \mathrm{cmol}_{\mathrm{c}} / \mathrm{dm}^{3}$; capacidade de troca catiônica $=5,98 \mathrm{cmol}_{\mathrm{c}} / \mathrm{dm}^{3}$; saturação de bases $=61,4 \% \mathrm{cmol}_{\mathrm{c}} / \mathrm{dm}^{3}$; cobre $=0,89 \mathrm{mg} / \mathrm{dm}^{3}$; ferro $37 \mathrm{mg} / \mathrm{dm}^{3}$; $28,3 \mathrm{mg} / \mathrm{dm}^{3}$; zinco $38,4 \mathrm{mg} / \mathrm{dm}^{3}$.

A implantação dos pastos ocorreu em janeiro de 2009, por meio de semeadura a lanço (30kg de sementes /ha). Foram realizadas três adubações (plantio, crescimento e manutenção), seguindo as recomendações descritas no Manual de
Adubação do Estado de Pernambuco (CAVALCANTI, 1998) para o capimbufel.

Os tratamentos experimentais constituíram-se em combinações de três ofertas de forragem (OF) $(4 ; 8$ e $12 \mathrm{~kg}$ de MS/100kg de peso corporal) e duas cultivares de capim-bufel (Biloela e Cpatsa 7754) distribuídas em arranjo fatorial $3 \times 2$ e delineamento em blocos casualizados com três repetições, sendo cada piquete uma unidade experimental. $\mathrm{O}$ método de pastejo utilizado foi o contínuo com o uso da técnica "put and take", para o ajuste das taxas de lotação dos pastos (MOTT \& LUCAS, 1952). Os ajustes do número de animais nos piquetes foram realizados a cada 28 dias, de acordo com os valores de massa de forragem dos pastos (MF) e de OF. Para os cálculos de OF foi utilizado o NRC (2007). Os valores de MF para cada cultivar e OF estão apresentado na Tabela 1.

Foram utilizados 52 ovinos (entre animais testes e reguladores), machos, castrados, sem raça definida (SRD) com peso corporal (PC) de 19,0 $\pm 3,0 \mathrm{~kg}$. Ao 
início do estudo os animais foram identificados com brincos auriculares numerados, pesados e receberam aplicação de anti-helmíntico.

O consumo de matéria seca (CMS) de forragem foi estimado por meio da utilização de bolsas coletoras de fezes, sendo que as coletas foram efetuadas a cada 28 dias, por um período de 12 meses. Foram utilizados três animais por tratamento, realizando a coleta durante três dias consecutivos. As fezes foram recolhidas duas vezes ao dia, pesadas, amostradas individualmente e encaminhadas ao Laboratório de Nutrição Animal da Embrapa Semiárido para a determinação dos teores de matéria seca, de acordo com as metodologias descritas por Silva \& Queiroz (2002). O consumo de matéria seca foi estimado por meio da seguinte equação: $\mathrm{CMS}=\mathrm{PF} /(1-\mathrm{DIVMS})$, sendo: CMS = consumo de matéria seca, $\mathrm{PF}=$ produção de fezes e DIVMS = digestibilidade in vitro da matéria seca da forragem (DETMANN et al., 2001).

Tabela 1. Massa de forragem de duas cultivares de capim-bufel manejadas em três ofertas de forragem

\begin{tabular}{|c|c|c|c|c|}
\hline \multirow{2}{*}{ OF (\%) } & Cultivar & Kg de MS/ha & \multirow{2}{*}{$\mathrm{CV}(\%)$} & \multirow{2}{*}{$\mathrm{P}$} \\
\hline & Biloela & Cpatsa 7754 & & \\
\hline 4 & $903,08^{c}$ & $977,13^{\mathrm{c}}$ & 43,00 & $<0,001$ \\
\hline 8 & $1403,22^{\mathrm{b}}$ & $1238,09^{\mathrm{bc}}$ & 43,00 & $<0,001$ \\
\hline 12 & $2065,28^{\mathrm{a}}$ & $1132,49^{\mathrm{bc}}$ & 43,00 & $<0,001$ \\
\hline
\end{tabular}

Médias seguidas de mesma letra não diferem entre si ao nível de significância de 5\%, segundo teste de Tukey.

Os parâmetros do desempenho produtivo determinados foram ganho médio diário (GMD), ganho de peso total (GPT) e peso corporal final (PCF). $\mathrm{O}$ PCF foi o peso obtido na última pesagem do experimento. O GPT foi determinado por meio da subtração entre o PCF e o PCI (peso corporal inicial). O GMD foi determinado por meio da diferença de peso dos animais entre duas pesagens consecutivas, cujo valor foi dividido pelo número de dias transcorridos. Durante todo o período de estudo os animais foram pesados a cada 28 dias, sendo que cada pesagem obedeceu a um jejum prévio de pelo menos 16 horas.

Ao final da fase de coleta em campo (12 meses), os animais foram submetidos a novo jejum de sólidos por 16 horas antes de realizar a última pesagem. Imediatamente após a pesagem, os animais foram levados ao abate, realizado no abatedouro municipal de PetrolinaPE. Após atordoamento, sangria, esfola e evisceração dos animais as carcaças foram pesadas obtendo-se o peso da carcaça quente (PCQ). A partir desse peso foi calculado o rendimento de carcaça quente (RCQ), de acordo com a equação: $\operatorname{RCQ}(\%)=(\mathrm{PCQ} / \mathrm{PCA}) \times 100$, em que $\mathrm{PCA}=$ peso corporal de abate (OSÓRIO et al., 1998).

Foi avaliada a taxa de lotação, apresentada de três formas: em número de animais (TLO), em peso corporal (TPC) e unidade animal (TUA). Os valores de TLO são resultados dos ajustes que ocorreram a cada 28 dias com base na MF e OF. Considerando o peso dos animais foi obtido o valor de TPC e dividindo-se o valor do peso corporal dos ovinos por 450 chegou-se ao valor de taxa de lotação em UA/ha. 
Já o ganho de peso por unidade de área foi apresentado em $\mathrm{kg} / \mathrm{ha} / \mathrm{ano}$, de acordo com a seguinte equação: $\mathrm{GP} / \mathrm{ha} / \mathrm{ano}=$ GMD x 365 × TLO, em que GP = ganho de peso, GMD = ganho médio diário, 365 $=$ número de dias do ano e TLO = taxa de lotação em número de animais/ha.

$\mathrm{O}$ delineamento experimental utilizado foi o de blocos casualizados, com seis repetições. Cada piquete foi considerado como uma unidade experimental. As análises estatísticas foram realizadas por meio do programa estatístico SAS (SAS INSTITUTE, 2002), realizando a análise de distribuição normal dos dados, em seguida, a análise de variância e o teste de Tukey. Foram considerados como significativos valores de probabilidade inferiores a $5 \%(\mathrm{P}<0,05)$.

\section{RESULTADOS E DISCUSSÃO}

As cultivares, ofertas de forragem (OF) e as interações entre cultivares e $\mathrm{OF}$ não afetaram as variáveis relacionadas com o consumo de forragem, o desempenho produtivo dos ovinos, os parâmetros de carcaça, taxa de lotação (ovinos/ha) e o ganho de peso por unidade de área (kg/ha/ano).

Em relação as duas cultivares avaliadas, Biloela e Cpatsa 7754, os valores observados para todas as variáveis avaliadas não foram significativos (Tabela 2). Contudo, o consumo de forragem está abaixo do que pode ser observado no NRC (2007). As médias de consumo dos animais em pastos de Biloela e CPATSA 7754 foram de $447,77 \mathrm{~g}$ e 462,84g de MS/animal/dia, respectivamente. Ou seja, menos de $2 \%$ em relação ao peso corporal dos animais. De acordo com o NRC (2007), o consumo de MS para ovinos com características semelhantes aos utilizados neste trabalho é de $630 \mathrm{~g}$ de MS/animal/dia, correspondendo a 3,16 \% do seu PV.

Trabalhando com ovinos sem raça definida (SRD), alimentados com o capim-bufel e leucena, Lira (1990) obteve consumo de $2,63 \% \mathrm{PV}$, valor superior ao encontrado no presente trabalho. Almeida et al. (2011) trabalhando com ovinos Santa Inês em pasto de Urocloa (Urochloa mosambicensis (Hack.) Dandy), também encontraram valores de ingestão de matéria superiores aos observados neste estudo.

Tabela 2. Consumo de forragem, desempenho produtivo e parâmetros de carcaça de ovinos mantidos e pastos de duas cultivares de capim-bufel, além da taxa de lotação e produção de carne por unidade de área dessas pastagens

\begin{tabular}{lccc}
\hline \multirow{2}{*}{ Item } & \multicolumn{2}{c}{ Cultivar } & \multirow{2}{*}{ CV $(\%)$} \\
\cline { 2 - 3 } & Biloela & Cpatsa 7754 & \\
\hline Consumo de forragem g de MS/animal/dia) & $447,77^{\mathrm{a}}$ & $462,84^{\mathrm{a}}$ & 35,18 \\
Ganho médio diário, g/animal & $54,12^{\mathrm{a}}$ & $68,04^{\mathrm{a}}$ & 30,16 \\
Ganho de peso total, kg/animal & $16,63^{\mathrm{a}}$ & $16,88^{\mathrm{a}}$ & 46,98 \\
Peso corporal final, kg & $34,19^{\mathrm{a}}$ & $37,08^{\mathrm{a}}$ & 24,53 \\
Peso de carcaça quente, Kg & $16,81^{\mathrm{a}}$ & $18,08^{\mathrm{a}}$ & 14,35 \\
Rendimento de carcaça quente, \% & $41,47^{\mathrm{a}}$ & $41,56 \mathrm{a}$ & 8,21 \\
Taxa de lotação, animal/ha & $12,5^{\mathrm{a}}$ & $11,07^{\mathrm{a}}$ & 30,40 \\
Produção de carne, kg/ha & $209,03^{\mathrm{a}}$ & $202,26^{\mathrm{a}}$ & 25,26 \\
\hline Médias na mesma linha, seguidas de mesma letra, não diferem entre si ao nível de significância de 5\%, \\
segundo teste de Tukey. CV = coeficiente de variação. & &
\end{tabular}


Ao início do estudo os valores de consumo de forragem foram superiores a $600 \mathrm{~g}$ de $\mathrm{MS} / \mathrm{animal} / \mathrm{dia}$, superior a $3 \%$ do peso corporal dos ovinos (Figura 2), já que o peso corporal foi inferior a $20 \mathrm{~kg}$. Entretanto, nos meses seguintes entre outubro e dezembro de 2009 os valores de consumo apresentaram queda acentuada, sobretudo para os animais mantidos nos pastos de capim-bufel Biloela manejado com OF de $4 \%$ que consumiram 200g de MS/animal/dia, valor semelhante ao apresentado pelos mantidos nos pastos dessa mesma cultivar manejado com $\mathrm{OF}$ de $8 \%$, no mês de novembro de 2009 .

Possivelmente, essa redução no consumo de forragem após o primeiro mês de avaliação se deu pela alteração na composição estrutural da planta com redução da proporção de folhas e, em consequência, da massa de folhas associada a possível perda de valor nutritivo da planta forrageira durante esse período, já que houve pouca precipitação pluvial, deixando a forragem mais seca.

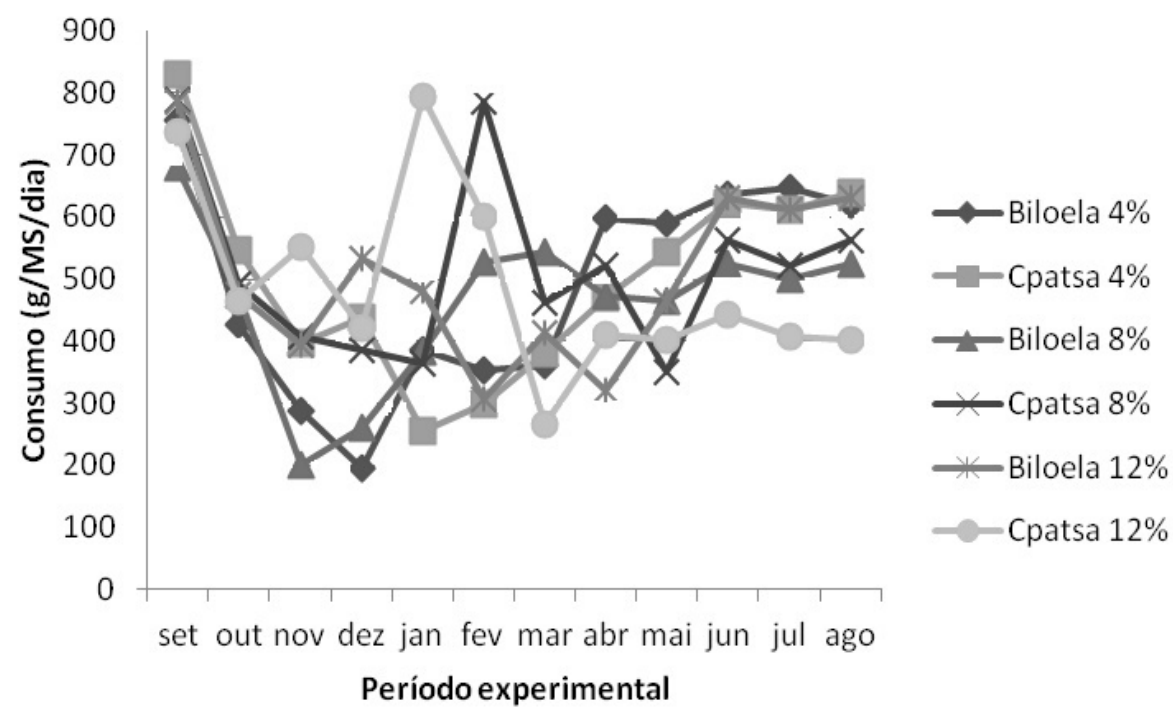

Figura 2. Consumo de forragem (kg de MS/animal/dia) de ovinos mantidos em pastos de duas cultivares de capim-bufel manejados com três ofertas de forragem

A partir do mês de dezembro, com as primeiras chuvas contribuindo com a rebrota do capim-bufel, o consumo de forragem começou a ser incrementado, especialmente para os animais mantidos nos pastos de Cpatsa 7754 manejados com OF de $12 \%$ e $8 \%$ (Figura 2). Provavelmente, os animais dessas áreas se beneficiaram por uma melhor resposta em termos de massa de forragem ou massa de folhas.
$\mathrm{Na}$ maioria dos meses, especialmente entre abril a agosto de 2010, o consumo de forragem ficou entre $400 \mathrm{~g}$ e $600 \mathrm{~g}$ de MS/animal/dia (Figura 2), valores inferiores aos do início do estudo e menores que o esperado, com menores valores apresentados pelos animais dos pastos com capim Cpatsa 7754 e OF de $12 \%$ em decorrência da menor participação de capim-bufel na área e da pouca MF nesses pastos. Os ovinos 
mantidos nos pastos de Biloela nas três OF avaliadas tiveram os maiores consumos nos últimos meses do estudo devido às maiores MF dessa planta forrageira que permitiu maior consumo de forragem (Figura 3).

A elevação na quantidade de forragem ofertada propicia incremento no ganho de peso dos animais, até se tornar estável, sobretudo nas ofertas de forragem mais altas. No entanto, nesta situação pode ocorrer diminuição no ganho por animal em decorrência do acúmulo de forragem de baixa qualidade ao longo da estação de crescimento. A presença de alta proporção de colmos, associada a baixa densidade de folhas dificulta a apreensão, causando decréscimo no tamanho dos bocados, acarretando baixo consumo de forragem (STOBBS, 1973; T'MANNETJE \& EBERSOHN, 1980; BURNS \& SOLLENBERGER, 2002).

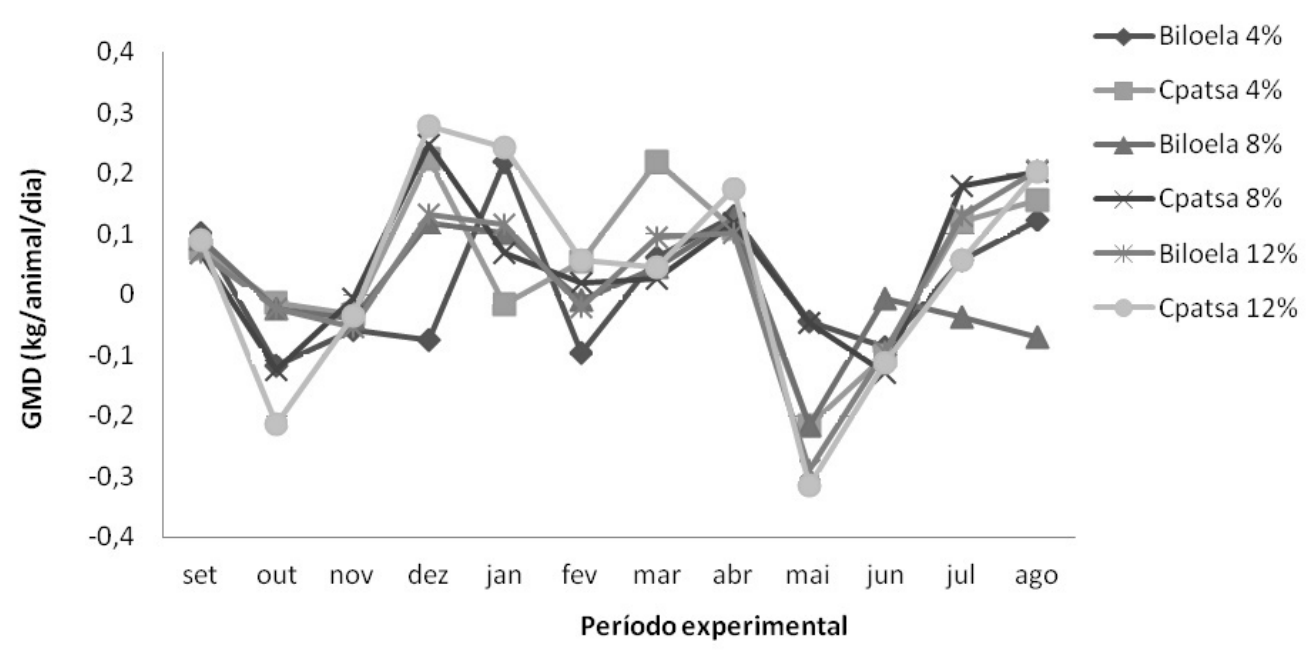

Figura 3. Ganho médio diário (GMD) de ovinos mantidos em pastagens de capim-bufel sob três ofertas de forragem (4\%, $8 \%$ e $12 \%$ ) e duas cultivares (Biloela e Cpasta 7754)

Em relação ao GMD, os valores obtidos no presente estudo estão condizentes com os apresentados por Souza \& Espíndola (1999) e por Voltolini et al. (2010) que avaliaram o desempenho produtivo de cordeiros mantidos em pastos de capimbufel no Semiárido brasileiro e relataram valores de GMD da ordem 50g/animal/dia. Possivelmente, os semelhantes consumos de forragem foram os responsáveis pelos semelhantes ganhos de pesos obtidos, os quais, em consequência promoveram ganhos de pesos totais, pesos corporais finais $\mathrm{e}$ pesos de carcaça quente também semelhantes $(\mathrm{P}>0,05)$.
No primeiro mês do estudo os ganhos dos ovinos foram da ordem de $100 \mathrm{~g} / \mathrm{animal} / \mathrm{dia}$, os quais sofreram queda nos meses seguintes em virtude dos menores consumos de forragem promovendo perda de peso aos animais. Entre os meses de dezembro de 2009 a abril de 2010 os animais retomaram os ganhos de peso em decorrência do período chuvoso e da rebrota dos pastos, menos no mês de fevereiro de 2010 que os animais também perderam peso, o que pode estar relacionado com a menor proporção de folhas na MF.

Em maio e junho de 2010 os ovinos voltam a apresentar perda de peso o que 
pode estar relacionado com os menores volumes de precipitação na área a partir de maio. No mês de maio foram registrados menos de $20 \mathrm{~mm}$ de chuva no mês e pouco mais que $20 \mathrm{~mm}$ em junho, promovendo menos rebrota ao capim, menor proporção de folhas na MF e prejudicando a composição químicobromatológica dos pastos. Ao final do estudo os ganhos são positivos para a maioria dos tratamentos, porém inferiores a $100 \mathrm{~g} / \mathrm{anima} /$ dia.

Pesos corporais finais entre 30 a 40kg são apreciados na região em decorrência da forma predominante de preparo e uso das carcaças ovinas. Pesos de carcaça quente para ovinos abatidos em média com $35 \mathrm{~kg}$ e rendimentos de carcaça quente da ordem de $42 \%$ estão em acordo com os valores obtidos por Voltolini et al. (2010) que trabalharam com ovinos de genótipos naturalizados do Semiárido brasileiro e observaram rendimentos de carcaça inferiores a $40 \%$. Provavelmente, no presente estudo os rendimentos foram superiores aos encontrados no estudo de Voltolini et al. (2010) por serem animais mais pesados e, possivelmente, com melhor acabamento de carcaça.

As taxas de lotação obtidas foram superiores a 10 ovinos/ha ao longo do ano, enquanto os pastos de capim-bufel permitiram pouco mais de $200 \mathrm{~kg}$ de ganho por/ha/ano o que está de acordo com os valores apresentados por Oliveira (2005) que relatam para bovinos taxas de lotação de 1 bovino adulto/ha e entre 200 a $300 \mathrm{~kg}$ de ganho de peso. Sousa \& Espíndola (2000), que trabalharam no Estado do Ceará com o pastejo de ovinos sem padrão racial definido sob três taxas de lotação em pastagens de capim-bufel, observaram GMD (g/animal/dia) de 42,4, 19,5 e 16,6 para as taxas de lotação de 4, 6 e 10 animais por hectare, respectivamente e produção de carne (kg/ha) de 40,4, 27,6 e 39,0 para as taxas de lotação de 4, 6 e 10 animais por hectare, respectivamente. Valores estes bem abaixo dos encontrados no presente estudo.

Para as OF, nenhuma característica estudada foi afeta $(\mathrm{P}>0,05)$. Já para o GMD foi observado comportamento semelhante ao GPT, pois apesar da OF de $12 \%$ permitir valores de GMD de 69,63 g/animal/dia eles não foram diferentes dos 53,43 g/animal/dia apresentados pelos animais mantidos nos pastos com OF de 4\% (Tabela 4).

Tabela 4. Consumo de forragem, desempenho produtivo e parâmetros de carcaça de ovinos mantidos e pastos de duas cultivares de capim-bufel, além da taxa de lotação e produção de carne por unidade de área desses pastos

\begin{tabular}{lcccc}
\hline \multirow{2}{*}{ Item } & \multicolumn{3}{c}{ Ofertas de forragem $(\%)$} & \multirow{2}{*}{$\mathrm{CV}(\%)$} \\
\cline { 2 - 4 } & 4 & 8 & 12 & \\
\hline Consumo de forragem, g de MS/animal/dia & $428,74^{\mathrm{a}}$ & $447,20^{\mathrm{a}}$ & $474,15^{\mathrm{a}}$ & 35,18 \\
Ganho médio diário, kg/animal & $53,43^{\mathrm{a}}$ & $53,66^{\mathrm{a}}$ & $69,63^{\mathrm{a}}$ & 30,16 \\
Ganho de peso total, kg/animal & $14,68^{\mathrm{a}}$ & $15,68^{\mathrm{a}}$ & $20,19^{\mathrm{a}}$ & 46,98 \\
Peso corporal final, kg & $35,95^{\mathrm{a}}$ & $35,38^{\mathrm{a}}$ & $38,95^{\mathrm{a}}$ & 24,53 \\
Peso de carcaça quente, kg & $18,62^{\mathrm{a}}$ & $16,52^{\mathrm{a}}$ & $17,19^{\mathrm{a}}$ & 14,35 \\
Rendimento de carcaça quente, \% & $41,29^{\mathrm{a}}$ & $42,16^{\mathrm{a}}$ & $41,08^{\mathrm{a}}$ & 8,21 \\
Taxa de lotação, animal/ha & $12,88^{\mathrm{a}}$ & $11,86^{\mathrm{a}}$ & $10,61^{\mathrm{a}}$ & 30,40 \\
Ganho por área, kg/ha & $207,39^{\mathrm{a}}$ & $181,11^{\mathrm{a}}$ & $228,44^{\mathrm{a}}$ & 25,26 \\
\hline
\end{tabular}

Médias na mesma linha, seguidas de mesma letra, não diferem entre si ao nível de significância de 5\%, segundo teste de Tukey. CV = coeficiente de variação. 
Esses resultados assemelham-se aos encontrados por Costa et al. (2006), que avaliaram o efeito de diferentes taxas de lotação dos pastos sobre o ganho de peso de ovelhas da raça Morada Nova em pastagens de Brachiaria humidicola, e encontraram como valor ótimo a taxa de lotação de 13 animais por hectare. Ainda de acordo com os mesmos autores, taxas de lotação superiores a 18 animais por hectare são inviáveis, uma vez que deram início ao processo de degradação das pastagens.

Ao início do estudo as taxas de lotação superaram 30 ovinos/ha, 1,6 UA/ha ou $700 \mathrm{~kg}$ de peso corporal, entretanto, na maioria dos meses as taxas de lotação se mantiveram entre 5 a 10 ovinos/ha, 0,2 a $0,8 \mathrm{UA} / \mathrm{ha}$ ou 100 a $400 \mathrm{~kg}$ de peso corporal/ha (Figuras 4 a, b e c).
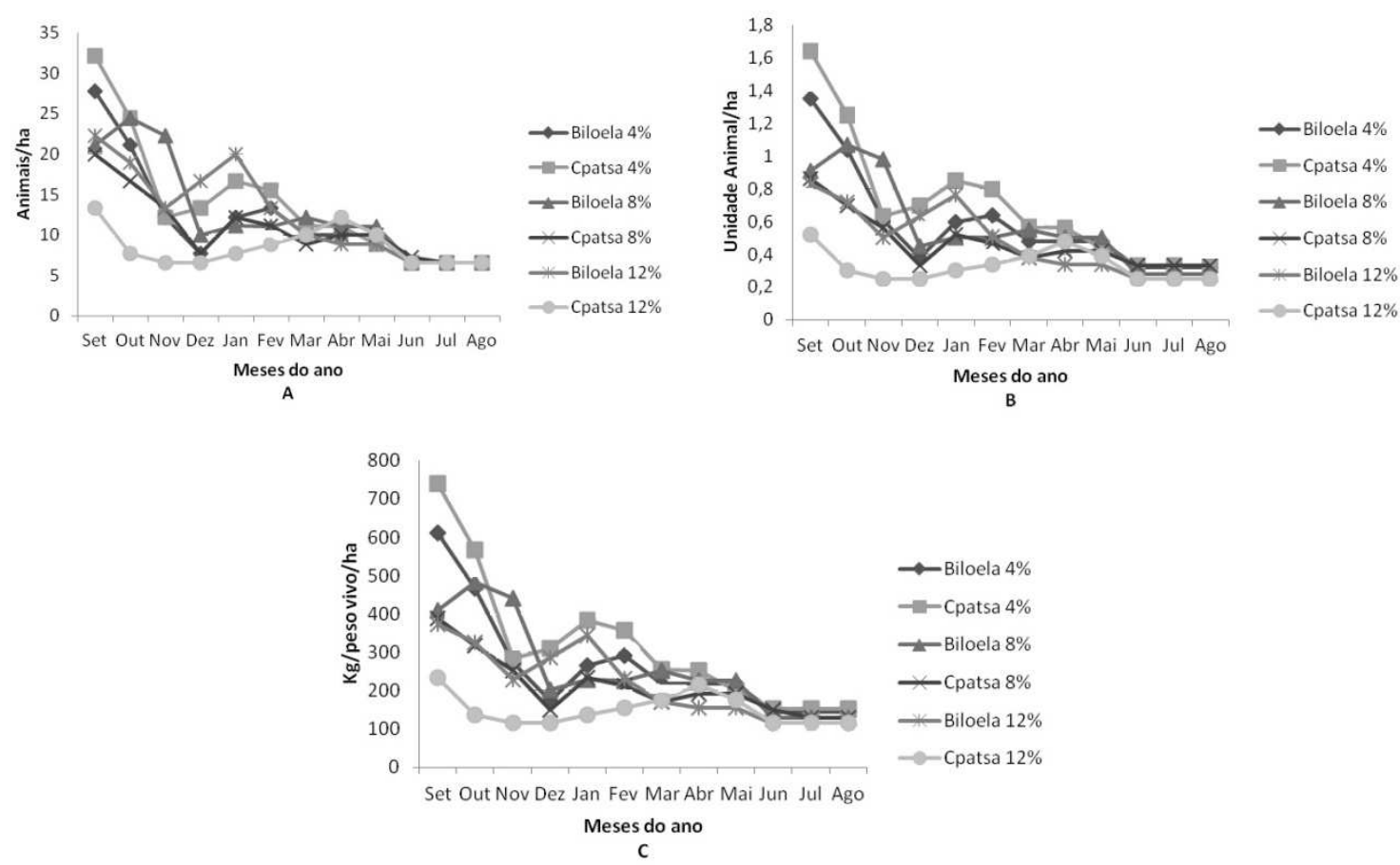

Figura 4. Taxa de lotação, representada em animais/ha (A), UA/ha (B) e kg/pc/ha (C), em pastagens de capim-bufel submetidas ao pastejo de ovinos sob três ofertas de forragem e duas cultivares

A ausência de diferenças estatísticas nos valores de taxa de lotação em função das OF se deram em decorrência de que em vários meses avaliados os pastos manejados na OF de $12 \%$ permitiram maior taxa de lotação e na média promoveram semelhantes taxas de lotação em relação às obtidas com menores OF. Nas menores OF o superpastejo prejudicou os pastos e em consequência a produção de forragem, já nas maiores $\mathrm{OF}$ os pastos apresentaram maiores MF e possibilitaram número de animais com peso corporal semelhante aos demais tratamentos na média do estudo.

As cultivares e as ofertas de forragem não influenciaram o consumo de forragem, $o$ desempenho produtivo e os parâmetros de carcaça de ovinos em pastos de capimbufel. As taxas de lotação e o ganho de peso por unidade de área de pastos de capim-bufel com ovinos também não 
Rev. Bras. Saúde Prod. Anim., Salvador, v.17, n.3, p.374-384 jul./set., 2016 http://www.rbspa.ufba.br ISSN 15199940

foram afetadas pelas cultivares de capimbufel e ofertas de forragem.

\section{AGRADECIMENTOS}

Embrapa Semiárido, UNIVASF e FACEPE.

\section{REFERÊNCIAS}

ALMEIDA, P.J.P.; PEREIRA, M.L.A.; AZEVEDO, S.T.; ALVES, E.M.; SOUZA, D.R. de; SANTOS, A.B. dos; PEREIRA, T.C. de J.; PEDREIRA, M. dos $\mathrm{S}$. Fontes energéticas suplementares para ovinos Santa Inês em pastagens de capim urocloa na época seca. Revista Brasileira de Zootecnia, v.12, n.1, p.140-154, 2011.

ANDRADE, I.S.; SOUZA, B.B.; PEREIRA FILHO, J.M. Parâmetros fisiológicos e desempenho de ovinos Santa Inês submetidos a diferentes tipos de sombreamento e a suplementação em pastejo. Ciência e Agrotecnologia, v.31, n.2, p.540-547, 2007.

BURNS, J.C.; SOLLENBERGER, L.E. Grazing behavior of ruminants and daily performance from warm-season grasses. Crop Science, v.42, p.873-881, 2002.

CAVALCANTI, F.J. de A. (Coord.). Recomendações de adubação para o Estado de Pernambuco. Recife: IPA, 1998. 198p.

COSTA, N.L.; MAGALHÃES, J.A.; PEREIRA, R.G.A.; TOWNSEND, C.R. Efeito da carga animal sobre o ganho de peso de ovelhas da raça Morada Nova em pastagens de Brachiaria humidicola (Rendle) Schweick. Revista Electrónica de Veterinaria, v.7, n.8, Agosto, 2006.
DETMANN, E.; PAULINO, M.F.; ZERVOUDAKIS, J.T. Cromo e indicadores internos na determinação do consumo de novilhos mestiços, suplementados, a pasto. Revista Brasileira de Zootecnia, v.30, n.5, p.1600-1609, 2001.

EMBRAPA. Centro Nacional de Pesquisa de Solos. Sistema Brasileiro de Classificação de Solos. 2 ed. Rio de Janeiro: Embrapa Solos, 2006.

EMBRAPA. Empresa Brasileira de Pesquisa Agropecuária. Disponível em: <https://www.embrapa.br/semiarido/lab oratorios/agrometeorologia>. Acesso em: 9 jan. 2011.

LIRA, R.C. Efeito da substituição do capim buffel (Cenchrus ciliaris L.) pela leucena (Leucaena leucocephala LAM. DE WIT.), na composição química e digestibilidade avaliada em ovinos e caprinos sob confinamento. 1990. 112p. Dissertação (Mestrado em Zootecnia) - Universidade Federal Rural de Pernambuco, Recife.

MEDEIROS, H.R.; DUBEUX JR. J.C. Efeitos da fertilização com nitrogênio sobre a produção e eficiência do uso da água em capim-buffel. Revista Caatinga, v.21, n.3, p.13-15, 2008.

MOTT, G.O.; LUCAS, H.L. The design conduct and interpretation of grazing trials on cultivated and improved pastures. In: INTERNATIONAL GRASSLAND CONGRESS, 6., 1952, Pensylvania. Proceedings... Pensylvania: State College Press, 1952. p.1380-1395.

NATIONAL RESEARCH COUNCIL NRC. Nutrient requirements of small ruminants. Washington: National Academy of Sciences, 2007. 362p. 
Rev. Bras. Saúde Prod. Anim., Salvador, v.17, n.3, p.374-384 jul./set., 2016 http://www.rbspa.ufba.br ISSN 15199940

OSÓRIO, J.C.S.; OSÖRIO, M.T.M.; JARDIM, P. O. Métodos para avaliação da produção da carne ovina: in vivo na carcaça e na carne. Pelotas: UFPEL, 1998. 99p.

OLIVEIRA, M.C. de. Capim-búfel. In: KIILL, L. H. P.; MENEZES, E. A. (Eds). Espécies vegetais exóticas com potencialidades para o semi-arido brasileiro. Brasília, DF: Embrapa Informação Tecnológica, 2005. 340p.

SANTOS, P.M.; VOLTOLINI, T.V.; CAVALCANTE, A.C.R.; PEZZOPANE, J.R.M.; MOURA, M.S.B.de.; SILVA, T.G.F. da.; BETTIOL, G.M.; CRUZ, P.G.da. Mudanças climáticas e a pecuária: Cenários futuros para o Semiárido brasileiro. Revista Brasileira de Geografia Física, v.6, p.1176-1196, 2011.

SILVA, T.C. da.; EDVAN, R.L.; MACEDO, C.H.de O.; SANTOS, E.M.; SILVA, D.S.da.; ANDRADE, A.P. Características morfológicas e composição bromatológica do capim buffel sob diferentes alturas de corte e resíduos. Revista Trópica - Ciência Agrárias e Biológicas, v.5, n.2, p.3039, 2011.

SILVA, D.J.; QUEIROZ, A.C. Análise de Alimentos: métodos químicos e biológicos. Viçosa, MG: Universidade Federal de Viçosa, 2002. 235p.

SOUZA, A.A. de.; ESPINDOLA, G.B. Efeito da suplementação com feno de leucena (Leucaena leucocephala (Larn) de Wit) durante a estação seca sobre o desenvolvimento ponderal de ovinos. Revista Brasileira de Zootecnia, v.28, n.6, p.1424-1429, 1999.
SOUZA, A.A. de.; ESPINDOLA, G.B. Bancos de Proteína de Leucena e de Guandu para Suplementação de Ovinos Mantidos em Pastagens de CapimBuffel. Revista Brasileira de

Zootecnia, v.29, n.2, p.365-372, 2000.

SAS. Statistical Analysis System. SAS user's guide: Stat. Version 9.1, 4.1.ed. Cary, NC: SAS Institute, 2002. 466p.

STOBBS, T.H. The effect of plant structure on the intake of tropical pastures. I. Variation in bite size of grazing cattle. Australian Journal of Agriculture Research, v.24, p.809-819, 1973.

T'MANNETJE, L.; EBERSONH, J.P. Relations between sward characteristics and animal production. Tropical Grassland, v.14, p.273-280, 1980.

VOLTOLINI, T.V.; MORAES, S.A.; ARAÚJO, G.G.L.de.; OLIVEIRA, P.L.T.de.; PEREIRA, L.G.R. Urea levels in multiple supplement for lambs grazing on Buffel grass. Acta Scientiarum.Animal Science, v.32, n.4, p.461- 465, 2010.

VOLTOLINI, T.V.; MORAES, S.A.; ARAÚJO.G.G.L.; PEREIRA, L.G.R. Concentrate levels for lambs grazing on Buffel grass. Revista Ciência Agronômica, v.42, n.1, p.216-222, 2011.

Data de recebimento: 31/07/2015

Data de aprovação: 22/07/2016 